\title{
De dokter als economisch medicus: van autonoom arts tot aanbieder op een markt
}

\section{Ed Vosselman}

SAMENVATTING Een kostprijs kan een belangrijke rol spelen bij het inperken van de professionele autonomie van medici. Dit accountinginstrument levert in zekere zin een vorm die over de inhoud regeert. Buitenstaanders (dat wil zeggen actoren van buiten de medische professie) kunnen het instrument gebruiken om de doelmatigheid van zorgactiviteiten te beïnvloeden. Tot die buitenstaanders behoren overheidsorganen die in een context van benchmarking en/of bekostiging invloed willen uitoefenen. Die invloed krijgt vooral gestalte via processen van standaardisering en economisering. De kring van beïnvloedende buitenstaanders kan worden uitgebreid via de invoering van marktwerking. De resulterende versterking van de transformatie van een 'geneeskunst' in een 'geneeskunde' heeft doelmatigheidsvoordelen, maar kan ook ongewenste neveneffecten hebben.

1

\section{Inleiding}

In de gezondheidszorg is al jaren de roep om kostenbeheersing hoorbaar. Onder invloed van diverse factoren stijgen de kosten van de zorg gestaag. Nederland 'vergrijst' en dat heeft tot gevolg dat het beslag op zorgfaciliteiten toeneemt. Voorts is er een explosie van nieuwe, kostbare medische technologie en ontwikkelt de genetica zich in een razendsnel tempo. Ook de verwachtingen van (potentiële) patiënten zijn steeds hoger gespannen; gezondheid is een hoog goed en men verwacht de beste diagnoseen behandeltechnieken.

Een overheid die het tot haar verantwoordelijkheid rekent om de doelmatigheid van de zorg te beïn-

Prof. dr. E.G.J. Vosselman is hoogleraar Accounting aan de Radboud Universiteit Nijmegen vloeden en te bewaken, moet er terdege rekening mee houden, dat de zorgsector wordt gedomineerd door medische professionals. Een professie kan worden omschreven als een exclusieve beroepsgroep die enigszins abstracte kennis op specifieke gevallen toepast (zie Abbott, 1988, p. 8). Omdat die kennis niet zomaar voor iedereen toegankelijk is, vormt de professie in feite een elite die door haar handelen een sterke invloed uitoefent op de kosten van de sector waarin zij werkzaam is. Die invloed is er zowel direct als indirect. Direct, omdat de werkzame professionals beslissingen nemen over diagnose- en behandelactiviteiten in concrete gevallen. Daarmee leggen zij ook het beslag op middelen, en dus de hoogte van de kosten, vast. Indirect, omdat de medische professie mede op basis van wetenschappelijk onderzoek nieuwe diagnose- en behandelmethoden ontwikkelt met toekomstige economische consequenties. De nieuwe methoden en technieken worden vervolgens ook overgedragen op toekomstige professionals door middel van een universitaire opleiding.

Een overheid die echt werk wil maken van kostenbeheersing in de zorg zal naar wegen moeten zoeken om de professie succesvol te beïnvloeden. Zij zal op zoek gaan naar mogelijkheden om externe druk op de professionals uit te oefenen, om zo te bewerkstelligen dat die professionals de doelmatigheid van zorgactiviteiten serieus meewegen in hun beslissingen. Dat heeft uiteraard tot gevolg dat hun autonomie wordt ingeperkt.

In dit artikel wordt onderzocht hoe de overheid kan bewerkstelligen dat er effectieve externe druk op de medische professie wordt uitgeoefend. Standaardisering en economisering van zorgactiviteiten blijken essentiële elementen in een dergelijk proces. Zij gaan gepaard met de constructie van representaties van die activiteiten. Zo'n representatie kan heel goed worden geconstrueerd met behulp van accountinginformatie en kan dan de vorm aannemen van bijvoorbeeld een kostprijs. De beschikbaarheid van een kostprijs maakt 
vervolgens de economisering van zorgactiviteiten mogelijk. Economisering treedt op wanneer de zorgactiviteiten in het verband van economische transacties worden geplaatst. De zorgactiviteit wordt dan gezien als de levering van een dienst (prestatie) waarvoor de ontvanger bereid is een prijs (tegenprestatie) te betalen. De economisering van de zorgactiviteiten kan vervolgens worden gecompleteerd door de inrichting van een markt en de introductie van marktwerking.

In de volgende paragrafen zal blijken dat standaardisering, economisering en de inrichting van (imperfecte) markten inderdaad tot een beperking van de autonomie van de medisch professionals leiden en anderzijds een effectieve beïnvloeding door andere belanghebbenden bij de zorg mogelijk maken. Wil die beïnvloeding doel treffen, dan is de beschikbaarheid van adequate informatie voor de belang hebbenden essentieel. Die informatie moet de zorgactiviteiten representeren. Daarom wordt in paragraaf 2 eerst aandacht besteed aan het genereren van dergelijke representatieve informatie en de macht die daarvan uit kan gaan. Paragraaf 3 geeft vervolgens een inkijk in de wijze waarop die informatie kan leiden tot standaardisatie van zorgactiviteiten. Paragraaf 4 gaat in op het waarom en het hoe van de economisering van de zorg en paragaaf 5 schetst contouren van een imperfecte zorgmarkt. In het bijzonder worden de voorwaarden voor een effectieve marktwerking besproken. Het artikel sluit af met conclusies en een korte discussie.

\section{Representatieve informatie: de macht van het symbool}

De overheid staat op grote afstand van het medisch handelen. Om gericht invloed te kunnen uitoefenen op de doelmatigheid van de zorg zal zij (of het orgaan dat zij daartoe in het leven roept en dat namens haar optreedt) op zijn minst abstracte informatie moeten hebben over de diagnose- en behandelactiviteiten. Die informatie betreft bijvoorbeeld de kosten van de activiteiten. Zo kan er informatie worden verzameld over de kosten van bepaalde chirurgische ingrepen, bijvoorbeeld de verwijdering van een ontstoken blinde darm. In aanvulling daarop kan informatie worden verzameld over de kosten van de verpleegkundige hulp die met een blindedarmoperatie is verbonden, over röntgenactiviteiten, over aanvullende geneeskundige behandelingen en over administratieve handelingen. Nog abstracter en nog meer 'samengebald' wordt die informatie, als zij het karakter van kostprijzen krijgt. Een kostprijs omvat de nood- zakelijke kosten per eenheid product (zie Asselman, 2007, voor een illustratie van een kostprijscalculatie in een academisch ziekenhuis). Daarom veronderstelt de beschikbaarheid van kostprijsinformatie niet alleen een ordening van zorgactiviteiten, maar ook een ordening van bundels van die activiteiten tot producten. Zo is het bijvoorbeeld mogelijk om de informatievraag verder te abstraheren van kosteninformatie over activiteiten tot informatie in de vorm van een kostprijs voor de behandeling van een ziektebeeld rond een blindedarmontsteking. Zo'n kostprijs omvat dan alle noodzakelijke kosten om iemand van een blindedarmontsteking te genezen. In feite representeert een kostprijs dus het middelenbeslag van een bepaalde bundel van activiteiten die rond het ziektebeeld van de blinde darmontsteking plaatsvindt. Een dergelijke bundel staat wel bekend als een Diagnose Behandeling Combinatie (DBC), door Schaepkens (2002, p. 19) omschreven als "het geheel van activiteiten van ziekenhuis en medisch specialist, voortvloeiend uit de zorgvraag waarvoor de patiënt de medisch specialist in het ziekenhuis consulteert".

De kostprijsinformatie staat in feite symbool voor het medisch handelen. Een symbool kan worden gezien als een verdichting van de echte activiteit. Het geeft daarvan een representatie. De echte concrete activiteit is in al haar nuances door de overheid (of meer in het algemeen door de actor op afstand) niet waar te nemen, de representatie wel. Latour (1987) stelt dat representatie een activiteit reduceert tot een vorm van die activiteit. Die vorm acteert dan in dit geval als een vertegenwoordiger van het medisch handelen. De kostprijs is als vertegenwoordiger van het medisch handelen een machtig instrument voor een 'speler op afstand', bijvoorbeeld een overheidsorgaan dat de kostprijs bij het ziekenhuis opvraagt en vervolgens verwerkt. Want dat orgaan zal de kostprijsinformatie als een onmiddellijke toegangspoort tot de wereld van het medisch handelen zien en kan die informatie benutten om institutionele druk te zetten. Zo kan de vorm dus in meer of mindere mate over de inhoud regeren. En precies daarin schuilt de macht van dergelijke representaties of symbolen (Douglas, 1982). Een 'actor op afstand' die zich ten doel heeft gesteld om de doelmatigheid in de gezondheidszorg te bevorderen kan op basis van kostprijsinformatie interveniëren zonder direct op de stoel van de medisch professional te gaan zitten. Terwijl zo ruimte wordt gelaten aan de lokale acties van de professionals is anderzijds interventie vanuit een 'centrum' (Latour, 1987) mogelijk. De mogelijkheden die het centrum heeft om te interveniëren verschillen in 
intensiteit. Een relatief passieve interventie kan bijvoorbeeld bestaan uit het verzamelen en vervolgens verspreiden van kostprijsinformatie bij en over de diverse lokale instellingen van gezondheidszorg. In feite is dan sprake van een vorm van 'benchmarking. Er ontstaat een rangorde van locale zorgcentra op basis van kostprijzen en dat kan competitieve krachten losmaken in de locale zorgcentra, hoe zwak ook. Die competitieve krachten maken het waarschijnlijk dat verschillen in doelmatigheid tussen de zorgcentra worden verkleind (zie ook Van Helden en Tillema, 2005). De locale eenheden met kostprijzen op of onder het gemiddelde zullen in beginsel tevreden zijn, hoewel zij wel de noodzaak zullen voelen hun prestatieniveau te handhaven en hun kostprijzen zo mogelijk nog wat te verlagen. De lokale eenheden met een kostprijs boven het gemiddelde zullen sterkere prikkels ervaren om de kostprijzen te verlagen; zij staan immers op achterstand.

Maar het centrum (in de zin van Latour) kan er ook voor kiezen om de competitieve strijd minder vrijblijvend te maken door additionele institutionele druk uit te oefenen. Dat kan zij bijvoorbeeld doen door de bekostiging van alle lokale zorgcentra te koppelen aan een norm. De kostprijs wordt dan op centraal niveau genormeerd (bijvoorbeeld op het gemiddelde van de locale kostprijzen) en die norm is bepalend voor de toewijzing van middelen aan de locale zorgcentra. In feite is er dan sprake van een vorm van outputbekostiging, een vorm die in Nederland in het verleden al in wisselende mate in de zorg is toegepast (zie bijvoorbeeld Groot, 1999 voor een overzicht van redenen voor en effecten van outputbekostiging). Wel moet worden vermeld, dat de definitie van de output in het geval van de DBC veel meer vanuit het perspectief van de patiënt, en dus vanuit de zorgvraag, plaatsvindt dan in het verleden het geval was. In het verleden werden parameters als opnames, verpleegdagen en eerste polikliniekbezoeken als outputmaatstaven gezien. In het systeem van de DBC's wordt het outputbegrip opgeschoven in de richting van de zorgvrager, de patiënt. Zoals Crom (2007) stelt, omvat de output nu alle "activiteiten, van het eerste consult of onderzoek tot en met de laatste (poliklinische) controle, van zowel medisch specialist als ziekenhuispersoneel, van zowel diagnostische als behandelactiviteiten".

\section{Standaardisering van zorgactiviteiten}

Hoe kan een lokaal ziekenhuis ervoor zorgen dat zij een beter plaatsje in de rangorde in gaat nemen? Of nog scherper: dat zij op of onder de gemiddelde kostprijs of 'norm'-kostprijs uitkomt? Een belangrijk hulpmiddel om dat te bewerkstelligen is de standaardisatie van zorgprocessen. Een dergelijk idee van standaardisatie ligt ook aan de basis van de ontwikkeling van DBC's, die in feite de Nederlandse verschijningsvorm zijn van de Diagnoses Related Groups (DRG's). DRG's zijn oorspronkelijk door 'industrial engineers' aan het eind van de jaren zestig geïntroduceerd in de Verenigde Staten van Amerika (Samuel et.al, 2005). Die introductie stond vooral in het teken van de gevoelde noodzaak om tot kwaliteitsbewaking te komen. De impuls daartoe werd gegeven door de subsidieverstrekker (de overheid). Die subsidieverstrekker wenste een zekere objectivering van het beslag op middelen in de gezondheidszorg en stelde zo'n objectivering als voorwaarde voor verdere subsidiering. De medische professie besloot daarop tot een beoordeling van hun werk door een andere beroepsgroep. Ter verkrijging van een dergelijke 'geobjectiveerde review' kozen de medische professionals voor de beroepsgroep van de ingenieur (en niet voor 'controllers' of 'cost accountants'), omdat die hen kon helpen aan effectieve industriële methoden van kosten- en kwaliteitsbeheersing. Het waren immers ook de ingenieurs die aan het begin van de twintigste eeuw aanmerkelijke efficiencyverbeteringen in industriële bedrijven konden realiseren met 'scientific management', en niet de controllers of 'cost accountants. Dus hoewel de DBC in onze tijd ook en misschien wel vooral wordt beschouwd als een accountingtechnologie (zie ook Preston,1992), dus als een instrument om tot kostprijzen te komen, is de DBC oorspronkelijk een middel tot standaardisatie geweest. Vanuit een ingenieursperspectief zijn de geneeskundige activiteiten, de diagnose en de behandelwijzen, te uniformeren en te stroomlijnen, evenals productieprocessen in een automobielfabriek. De opname en het ontslag van patiënten beschouwen zij als vergelijkbaar met de toevoer en de afvoer van auto's naar en van een assemblagelijn in een automobielfabriek. Daarmee maakte de bemoeienis van de beroepsgroep der ingenieurs het mogelijk om het medische handelen te objectiveren en het persoonlijke, individuele oordeel van een medicus in specifieke situaties meer naar de achtergrond te plaatsen. Dat heeft tot gevolg, dat voor de patiënt de kans dat hij in ziekenhuis A met andere diagnose- en behandelactiviteiten wordt geconfronteerd dan in ziekenhuis B, aanmerkelijk kleiner wordt. Bovendien heeft toepassing van protocollering een direct effect op de inzet van middelen. Via zo'n protocol wordt dus ook de doelmatigheid van de activiteiten van buitenaf, van buiten de professie, gestuurd. 
De kostprijs blijkt dus de macht in zich te dragen om lokale ziekenhuizen en de daar werkzame professionals aan te zetten tot standaardisering en protocollering. In die zin is de kostprijs dus geen reflectie van reeds ingerichte activiteiten, maar is zij omgekeerd een macht die tot constructie van activiteiten aanzet. Deze conclusie is vergelijkbaar met de conclusie van Crom (dit nummer) dat rekenkundige (output) budgetten geen reflectie zijn van de mate van takonzekerheid, maar dat de outputbudgettering juist helpt om taakonzekerheid te reduceren.

\section{Economisering van zorgactiviteiten}

Uiteraard hebben standaardisering en protocollering pas effect, als de 'professionals', de artsen, zich volgens het protocol gedragen. Om te bevorderen dat artsen dat doen kunnen prikkels ofwel 'incentives' worden ingezet. Zoals processen van standaardisatie sterk verbonden zijn met het gedachtegoed van de ingenieur, zo zijn processen van economisering sterk verbonden met het gedachtegoed van economen. Zo is het concept van de prikkel, de 'incentive', sterk gerelateerd aan de (economische) agentschapstheorie (o.a Jensen en Meckling 1976; Ross, 1973; Stiglitz, 1974). Basisveronderstelling in dit theoretisch denken is dat individuen (en dus ook individuele artsen) zich laten leiden door eigenbelang. Protocollering zou in deze theoretische visie dus succesvol kunnen zijn, als het eigenbelang van de arts (en/of van de organisatie waarin de arts werkzaam is) ermee is gediend. Goed gerichte prikkels die inspelen op dat eigenbelang en die aanzetten tot geprotocolleerd handelen doen dan het motiverende werk. Dergelijke prikkels moeten vooral worden gezocht in bekostigings- en beloningssystemen. Als de bekostiging voor een bepaalde geneeskundige activiteit en (dus) de beloning van de arts gebaseerd is op de gestandaardiseerde bundel van activiteiten en niet op de activiteiten zoals die werkelijk worden uitgevoerd, krijgt de arts in de economische redenering een prikkel om in ieder geval niet meer activiteiten te (laten) verrichten. Zo stimuleert een bekostigingssysteem dat is ontworpen rond DBC's en waarbij een bepaalde standaardprijs wordt betaald voor een gestandaardiseerde combinatie van diagnose- en behandelactiviteiten de neiging van de arts om volgens protocol te werken en geen onnodige activiteiten uit te (laten) voeren. De DBC-prijs (een kostprijs) omvat in wezen zowel de vergoeding voor de activiteiten van de arts als de vergoeding voor de overige noodzakelijke activiteiten en faciliteiten. Met andere woorden: het gaat niet alleen om de directe diagnose- en behandelactivi- teiten, maar ook om de zorgprocessen en administratieve processen eromheen, en om de faciliteiten (gebouwen en dergelijke) die nodig zijn om die activiteiten uit te kunnen voeren. Omdat menig arts niet in dienst is van het ziekenhuis, maar als economisch zelfstandige binnen de muren van het ziekenhuis opereert, zal de DBC-prijsprikkel zowel rechtstreeks het belang van de arts als dat van het ziekenhuis betreffen.

Kortom: het gedachtegoed van economen, zoals dat is verwoord in economische organisatietheorie waarin 'incentives' centraal staan en dat tot uitdrukking komt in een bekostigingssysteem zoals boven beschreven, kan bewerkstelligen dat artsen zich conform protocol gaan gedragen. Zoals de ingenieur kan helpen bij het ontwerp van gestandaardiseerde zorgprocessen en dus van protocollen, zo kan de econoom helpen bij het beïnvloeden van de professionals om zoveel mogelijk conform protocol te handelen. Het instrumentarium van de econoom sluit aan bij de gedachte, dat de arts een economisch individu, een 'economisch mens' is. Zo'n mens laat zich leiden door zijn economisch eigenbelang.

Aan prikkelsystemen zijn ook gevaren verbonden, dat weten juist ook economen maar al te goed. Want de economische mens is niet altijd helemaal te vertrouwen. Het individu (en waarom dus ook niet de medicus?) kan de notie van het eigenbelang soms oprekken tot opportunisme. De opportunist streeft zijn eigenbelang na op een wat arglistige wijze, met vormen van list en bedrog dus. Om er zelf beter van te worden onttrekt hij bepaalde informatie of bepaalde activiteiten aan het zicht. Hij kan ook bepaalde activiteiten onzichtbaar achterwege laten. Zo zou een opportunistisch ingesteld arts bepaalde in een DBC opgenomen activiteiten niet kunnen uitvoeren om tijd en middelen te sparen, terwijl hij toch de volledige bekostiging (baten) realiseert. Ook zou hij de wat meer complexe gevallen wel eens wat te weinig aandacht kunnen geven of ze zelfs niet kunnen accepteren. Want hoewel de diagnose- en behandelactiviteiten voor een bepaald ziektebeeld gestandaardiseerd zijn, kunnen individuele ziektegevallen natuurlijk toch sterk van elkaar afwijken. Een professioneel betrokken arts die in principe bereid is om volgens het protocol te werken, zal op grond van zijn professionele standaarden toch van zijn protocol af willen wijken om de patiënt naar behoren te kunnen helpen. Hier komt dan de 'medische mens', de ethisch handelend professional, in conflict met de 'economische mens', de mens die zijn belangen zo goed mogelijk tracht te behartigen. 
Uit onderzoek (Ghoshal en Moran, 1996; Frey en Jegen, 2001; Osterloh en Frey, 2004) blijkt dat prikkelsystemen intrinsieke motivatie en betrokken gedrag kunnen ondermijnen en opportunistisch gedrag kunnen oproepen. Als gevolg van de externe prikkels verschuift de aandacht van de medische activiteiten zelf naar de beloning voor die activiteiten, in dit geval het bekostigingssysteem. Daarmee is de 'economische mens' geen statisch verschijnsel; hij kan worden geconstrueerd of op zijn minst een handje worden geholpen in zijn ontwikkeling. Op grond hiervan kan de voorzichtige verwachting worden geformuleerd dat prikkelsystemen de potentie in zich dragen het verantwoord professionele gedrag van artsen aan te tasten. Want de introductie van prikkels in de gezondheidszorg zal ertoe leiden, dat de 'economische mens' zich zal gaan mengen met de 'professionele mens'. Zo ontstaat de hybride professional, die een menging is van arts en econoom. Toekomstig wetenschappelijk onderzoek zal moeten leren, of terreinwinst van de 'economische mens' in dit mengsel het ethisch-professioneel handelen in de weg kan komen te staan. Kunnen protocollering en economisering van zorgactiviteiten de kwaliteit van zorg aantasten? Hoeveel van de economische mens kan de medisch professional verdragen?

Natuurlijk kan men redeneren, dat de medicus al sinds jaar en dag een mengsel van een economische mens en een professionele mens is. Hij is immers ook in het verleden heel vaak een economisch zelfstandige. Dus wat is eigenlijk het probleem? Waarom zou economisering van zorgactiviteiten zoals boven beschreven de zaak kunnen verergeren? Het antwoord op die vraag ligt in de instrumentele context: in het verleden ging de economische zelfstandigheid gepaard met een hoge mate van professionele autonomie, nu gaat economisering gepaard met een inperking van de professionele autonomie. In het verleden bekrachtigde de economische zelfstandigheid het autonome professionele handelen omdat de arts zo buiten de hiërarchie van het ziekenhuismanagement werd geplaatst. De economisering van zorgactiviteiten als boven beschreven ontkracht evenwel die professionele autonomie. Zij staat in het teken van de beïnvloeding van het gedrag van de arts door nietprofessionals, door buitenstaanders. Een dergelijke beïnvloeding kan door de arts worden gevoeld als een instrumentele bejegening en dat kan juist opportunistisch gedrag oproepen.

Groenewegen (2007) formuleert een vergelijkbare hypothese. Die luidt dat "(markt)contracten die zijn gebaseerd op het beginsel van wantrouwen (en daardoor 'dichtgetimmerd' moeten worden), de cultuur van betrokkenheid en de beroepsethiek ondergraven". Toekomstig onderzoek kan meer zicht geven op de mate waarin een dergelijke effecten optreden.

\section{Marktwerking in de gezondheidszorg}

Voor een bekostiging gekoppeld aan DBC's is het in beginsel niet noodzakelijk om marktwerking in te richten. De prijzen voor een DBC kunnen immers worden vastgesteld door een overheidsorgaan (het 'centrum'), die de prijzen vervolgens aan alle ziekenhuizen oplegt. De economische prikkeling kan evenwel worden versterkt door de prijsvaststelling meer decentraal te laten plaatsvinden en door marktcompetitie te introduceren. Een dergelijke competitie kan worden gerealiseerd als patiënten of hun vertegenwoordigers de mogelijkheid hebben om 'met de voeten te stemmen'. Er ontstaat dan een 'uitgangsdreiging. Als de opdrachtgever, in dit geval de patiënt of diens vertegenwoordiger, ontevreden is over de prijs/ kwaliteitsverhouding van de geleverde zorg, heeft hij de mogelijkheid om naar een andere kraam, een andere zorgaanbieder, te gaan. Die dreiging om bij de aanbieder weg te lopen, die uitgangsdreiging, disciplineert de aanbieder om goede zorg tegen een concurrerende prijs te leveren.

Om tot effectieve marktwerking te komen, moet er uiteraard aan een aantal voorwaarden worden voldaan. In de eerste plaats moeten er genoeg zorgaanbieders zijn waaruit de patiënt daadwerkelijk een keuze kan maken. Aan deze voorwaarde is in het algemeen voldaan, zij het dat een acute intramurale zorgvraag vaak noodzakelijkerwijs bij de dichtstbijzijnde aanbieder terecht moet komen en dat bepaalde vormen van specialistische zorg zich concentreren bij één of enkele zorgaanbieders. Een voorbeeld van dergelijke geconcentreerde specialistische zorg is die van het oogziekenhuis in Rotterdam. In de tweede plaats moet de vrager naar zorg en/of diens vertegenwoordiger zicht hebben op de aard en de kwaliteit van het zorgaanbod zoals dat door de diverse aanbieders wordt verstrekt. Dat zicht is er inderdaad vooral bij de vertegenwoordigers van (potentiële) patiënten. Dat zijn de verzekeringsmaatschappijen, die professionele beschouwers van de aard en kwaliteit van de zorg in dienst hebben. Die beschouwers zijn zelf medisch geschoold. De verzekeringsmaatschappijen sluiten raamcontracten met die instellingen voor zorgverlening af die in hun waarneming kwalitatief goede zorg verlenen tegen een redelijke prijs. De transacties die door die raamcontracten worden bestuurd betreffen in feite de levering van DBC's ten behoeve van de bij de verzekeringsmaatschappijen 
aangesloten verzekerden. Voor elk van die bundels diagnose- en behandelactiviteiten wordt op basis van onderhandeling een prijs bepaald. Bezien vanuit de verzekeringsmaatschappijen wordt het onderhandelen effectiever naarmate de professionele inkoper meer zicht heeft op de aard en de kwaliteit van het zorgaanbod.

In de raamcontracten die met de zorgaanbieders worden gesloten, worden niet alleen afspraken gemaakt over de levering van DBC's en de prijzen van die DBC's, maar worden ook allerlei aanvullende afspraken gemaakt die de vrijheidsgraden van de zorgaanbieder kunnen beperken. Voorts is de 'exit threat', de uitgangsdreiging, een belangrijk disciplinerend machtsmiddel. Uit de economische organisatietheorie, met name de transactiekostentheorie (Williamson, 1996), is het inzicht geboren dat de effectiviteit van de uitgangsdreiging en dus de effectiviteit van marktwerking vooral wordt bepaald door de transactiespecificiteit van de investeringen die voor een bepaalde transactie of serie van transacties moeten worden gedaan. Het gaat hierbij zowel om investeringen in materiële middelen als om investeringen in immateriële zaken zoals bijvoorbeeld kennis. Hoe sterker de transactiespecificiteit van investeringen is, hoe meer partijen tot elkaar veroordeeld zijn. Naarmate de transactiespecificiteit van de investeringen toeneemt, is het immers minder goed mogelijk om te 'switchen' naar andere marktpartijen. Als partijen eenmaal een overeenkomst hebben gesloten, raken zij tot elkaar veroordeeld omdat een overstap naar een andere partij wel erg hoge kosten met zich mee zou brengen. Partijen vormen dan samen een soort bilateraal monopolie en in zo'n situatie gaat er niet of nauwelijks meer een disciplinerende werking van een markt uit. Dat geldt bijvoorbeeld voor topspecialistische zorg uit academische ziekenhuizen of voor specialistische algemene ziekenhuizen, zoals bijvoorbeeld het oogziekenhuis in Rotterdam. In dergelijke situaties zal de disciplinerende werking vooral uit de prikkelende of juist beperkende contractbepalingen moeten komen. De contracten zullen 'credible commitments' of geloofwaardige afspraken moeten bevatten die een goede prijs/kwaliteitsverhouding van de zorg stimuleren en bewaken. Een voorbeeld van een geloofwaardige afspraak is dat de zorgaanbieder zich bereid verklaart om de 'inkoper' van zorg, dus de verzekeringsmaatschappij, volledige openheid van zaken te geven over de ontwikkelingen in het zorgaanbod. Daartoe accepteert zij bijvoorbeeld dat een professional in dienst van de verzekeringsmaatschappij meewerkt in het ziekenhuis.
Groenewegen (2007) geeft een uitvoerige transactiekostentheoretische analyse van de invoering van marktwerking in de gezondheidszorg'; Brandenburg (2007) komt met door de transactiekostentheorie gevoede empirische inzichten.

Uiteraard heeft de markwerking ook een negatieve kant. De inrichting en werking van de markt brengt immers de nodige administratieve lasten met zich mee. Het gaat hier om allerlei soorten van kosten, zoals kosten van informatievergaring vooraf, registratiekosten bij de zorgaanbieder, kosten van onderhandelen, kosten van bewaking van de levering van de bundel van zorgactiviteiten, kosten die verbonden zijn aan het oplossen van conflicten.

Voorts is er een risico dat opportunistisch gedrag wordt opgeroepen. Want aan de basis van de invoering van marktwerking ligt een transformatie van een zorgrelatie in een klant-leverancierrelatie. Anders gezegd: marktwerking veronderstelt standaardisering en economisering van zorg en beide hebben de potentie om de beroepseer aan te tasten. De transformatie naar klant-leverancierrelaties construeert een 'economisch medicus' die zich in zijn gedrag op zijn minst gedeeltelijk laat leiden door externe prikkels. Dergelijke prikkels kunnen door medici worden ervaren als een vorm van georganiseerd wantrouwen en kunnen zo verantwoord professioneel gedrag uitdrijven. Maar nogmaals: de mate waarin deze eventuele effecten optreden is onderwerp van toekomstig onderzoek. Daarbij moet ook bedacht worden, dat in de Nederlandse situatie de bekostiging op basis van DBC's en de daarmee verbonden marktwerking wel heel geleidelijk worden ingevoerd.

\section{Conclusies en discussie}

Dit artikel bevat een analyse van de hoofdlijnen in de ontwikkeling naar meer externe, disciplinerende druk op professionele medici. Als gevolg van die ontwikkeling is de autonomie van de medische professie onmiskenbaar afgenomen. De macht van accountinginformatie, in het bijzonder van prijskaartjes aan DBC's, blijkt voor die ontwikkeling van groot belang. Want juist die informatie blijkt de mogelijkheid in zich te dragen om vanaf een afstand en van buiten de groep van de medische professionals de doelmatigheid van zorgactiviteiten te beïnvloeden. Accountinginformatie heeft die macht kunnen verkrijgen via processen van standaardisatie van zorgprocessen en van economisering van de zorg. Daarmee zijn het niet zozeer de administrateurs of controllers die de aanval op de autonomie van de 
medici hebben ingezet, maar de ingenieurs en de economen. Die invloed van ingenieurs en economen heeft geleid tot hybridisering van de medicus tot economisch medicus. Zij heeft de verdere ontwikkeling van een geneeskunst waarin het professionele oordeel en handelen van een individuele medicus doorslaggevend zijn naar een geneeskunde waarin protocollen centraal staan, mogelijk gemaakt en gefaciliteerd.

In Nederland is onder verantwoordelijkheid van het kabinet-Balkenende II een omvangrijke operatie naar meer marktwerking in de gezondheidszorg in gang gezet (doorvoering van het plan Hoogervorst). Het is nog veel te vroeg om de effecten van de invoering van marktwerking zoals die onderdeel is van het plan Hoogervorst te evalueren. Hoewel geconstateerd kan worden dat zich vele administratieve problemen rond de (prijzen van) DBC's hebben voorgedaan en nog voordoen, zal de toekomst moeten leren in hoeverre de administratieve problemen en lasten worden gecompenseerd door de baten: een meer doelmatige gezondheidszorg. Daarbij zal bovendien bewaakt moeten worden dat opportunisme het niet wint van verantwoord professioneel handelen. Uiteindelijk gaat het toch om die individuele patiënt, die een op zijn of haar ziektebeeld afgestemde zorg verwacht. Een op de persoon toegesneden kwalitatief goede zorg vereist meer dan de correcte toepassing van protocollen. Een medicus die een dergelijke zorg kan en wil verlenen herkent men aan zijn betrokkenheid richting zijn patiënten, aan zijn professionele intuïtie en vaardigheden en aan ethisch-professioneel handelen. Welke vruchten standaardisering en economisering ook kunnen leveren, het kan niet de bedoeling zijn dat die wezenlijke kunstzinnige elementen verdwijnen.

\footnotetext{
Literatuur

Abbott, A. (1988), The system of professions: an essay on the division of expert labor. Chicago: University of Chicago Press.

Asselman, F. (2007), Het ontwerp, implementatie en toepassing van een kostprijsinformatiesysteem in het Academisch Medisch Centrum, in: Maandblad voor Accountancy en Bedrijfseconomie, jg. 81, no. 3 (maart), dit themanummer.

Brandenburg, C. (2007), Zorgverzekeraars contracteren ziekenhuizen in een vrije markt. Een empirisch onderzoek naar de transactiekosten, in: Maandblad voor Accountancy en Bedrijfseconomie, jg. 81, no. 3 (maart), dit themanummer.

Crom, B. (2007), Taakonzekerheid en budgettering in ziekenhuizen, in: Maandblad voor Accountancy en Bedrijfseconomie, jg. 81, no. 3 (maart), dit themanummer.

Douglas, M. (1982), In the active voice, London: Routledge.
}

Frey, B. en R. Jegen (2001), Motivation crowding theory: a survey of empirical evidence, in: Journal of Economic Surveys, vol. 15, pp. 589-611. Ghoshal, S. en P. Moran, P. (1996), Bad for practice: a critique of the transaction cost theory, Academy of Management Review, vol. 21, no. 1, pp. 13-47.

Groenewegen, J. (2007), Transactiekostentheorie en de nieuwe zorgmarkt, in: Maandblad voor Accountancy en Bedrijfseconomie, jg. 81, no. 3 (maart), dit themanummer.

Groot, T.L.C.M. (1999), Budgetary reforms in the non-profit sector: a comparative analysis of experiences in health care and higher education in the Netherlands, Financial Accountability and Management, vol. 15, no. 3/4, pp. 353-376.

Helden, G.J. van, en S. Tillema, (2005), In search of a benchmarking theory for the public sector, Financial Accountability and Management, vol. 21, no. 3, pp. 337-361.

Jensen, M.C. en W.H. Meckling (1976), Theory of the firm: managerial behaviour, agency costs and ownership structure, Journal of Financial Economics, vol. 3, no. 4, pp. 305-360.

Latour, B. (1987), Science in action. Cambridge, MA: Harvard University Press.

Llewellyn, S. and D. Northcott, D. (2005), The average hospital, Accounting, Organizations and Society, vol. 30, no. 6, pp. 555-583.

Osterloh, M. en B. Frey (2004), Corporate governance for crooks? The case for corporate virtue, in: Grandori, A. (red.) Corporate governance and firm organization, Oxford University Press, pp. 191-211.

Preston, A.M. (1992), The birth of clinical accounting: a study of the emergence and transformation of discourses on costs and practices of accounting in US hospitals, Accounting, Organizations and Society, vol. 17, no. 1, pp. 63-100.

Ross, S. (1973), The economic theory of agency: the principal's problem, American Economic Review, vol. 63, pp. 134-139.

Samuel, S., M.W. Dirsmith, en B. McElroy (2005), Monetized medicine: from the physical to the fiscal, in: Accounting, Organizations and Society, vol. 30, no. 3, pp. 249-278.

Schaepkens, E.F.J.M. (2002), Ziekenhuisbekostiging in Nederland; van FB naar DBC, Management Control \& Accounting, vol. 6, no. 5 (oktober), pp. 13-24.

Stiglitz, J.E. (1974), Incentives and risk sharing in sharecropping, Review of Economic Studies, vol. 41, pp. 219-255.

Williamson, O.E. (1996). The Mechanisms of Governance, Oxford: University Press. 